\title{
ELECTRICAL CONDUCTIVITY AND ELECTROMAGNETIC SHIELDING EFFECTIVENESS OF BIO-COMPOSITES
}

\author{
EMUS 2019
}

\author{
KONSTANTINOS TSERPES ${ }^{*}$, VASILEIOS TZATZADAKIS ${ }^{*}$ AND JENS \\ BACHMANN ${ }^{\dagger}$ \\ * Laboratory of Technology \& Strength of Materials (LTSM) \\ Department of Mechanical Engineering \& Aeronautics \\ University of Patras \\ Patras, 26504, Patras, Greece \\ e-mail: kitserpes@upatras.gr \\ e-mail: mead6256@upnet.gr \\ ${ }^{\dagger}$ German Aerospace Center (DLR) \\ Institute of Composite Structures and Adaptive Systems \\ Lilienthalplatz 7, 38108 Braunschweig, Germany \\ e-mail: jens.bachmann@dlr.de
}

Key words: Bio-composites, Electrical conductivity, Electromagnetic shielding effectiveness

\begin{abstract}
In this paper, electrical conductivity and electromagnetic shielding effectiveness of two bio-composites have been studied by tests and numerical models. Two monolithic composites with partly bio-based content were manufactured. The first bio-composite is made of a carbon fibre fabric prepreg and a partly bio-based (rosin) epoxy resin (CF/Rosin). The second bio-composite is a combination of prepregs of carbon fibre fabric / epoxy resin and flax fibre fabric / epoxy resin (CF-Flax/Epoxy). A single line infusion process has been used prior to the curing step in the autoclave. Both variants are exemplary for the possibility of introducing bio-based materials in high performance CFRP. In-plane and out-of-plane electrical conductivity tests have been conducted according to Airbus standards AITM2 0064 and AITM2 0065, respectively. Electromagnetic shielding effectiveness tests have been conducted based on the standard ASTM D 4935-10. Materials were prepared at the German Aerospace Center (DLR) while characterization tests were conducted at the University of Patras. In addition to the tests, numerical models of representative volume elements have been developed using the DIGIMAT software to predict the electrical conductivity of the two bio-composites. The preliminary numerical results show a good agreement with the experimental results.
\end{abstract}

\section{INTRODUCTION}

Carbon-fiber reinforced plastics (CFRPs) are increasingly replacing metallic materials in lightweight structures. Bio-composite materials derived from natural, renewable sources such as bio-fibers and bio-resin have received significant interest in recent years, mainly due to the increased awareness of environmentally sustainable technologies, the weight reduction they offer, the added functionality and the occupational health benefits. However, they have not yet found their way in aircraft structures mainly due to their low mechanical properties, the lack of 
experience and confidence regarding their durability and the unknown electromagnetic properties $[1,2]$.

Electromagnetic (EM) penetration of aircrafts mainly comes from lightning effects. On the other hand, lightning discharges do not necessarily have to hit the aircraft structure directly to create EM fields. Intracloud discharges for example might produce intense high frequency radiation [3]. Additionally, to the lightning effects, an electromagnetically disturbed environment for the aircraft is developed from the infrastructure of all communication, entertainment and surveillance. EM radiation penetrates the aircraft from outboard groundbased transmitters for navigation, communication, radar surveillance from other aircrafts or satellite propagation as well as from onboard generated interferences appearing by the carried onboard communication and entertainment equipment. Whereas a metallic aircraft fuselage principally counters these EM fields like a faraday cage -through its high electrical conductivity is able to deflect and absorb the radiation and provides an EM shield- a composite fuselage is not able to counter EM fields without enhancement [4].

When passengers are exposed to the EM waves, the network of veins in high risk organs such as eyes might be affected. This is due to heat build-up in the eyes by the EM waves which could not be easily dissipated. In order to avoid these hazards to passengers and to protect the sensitive equipment from undesired EM radiation [5], EM interference shielding is essential. In order to block the undesired EM radiation, one has to understand the electrical properties and EM behavior of structural materials. In this work, the electrical conductivity and electromagnetic shielding effectiveness (EMSE) of two bio-composites, which are destined for use in secondary aircraf

\section{MATERIALS}

The first bio-composite

(rosin) epoxy resin (er
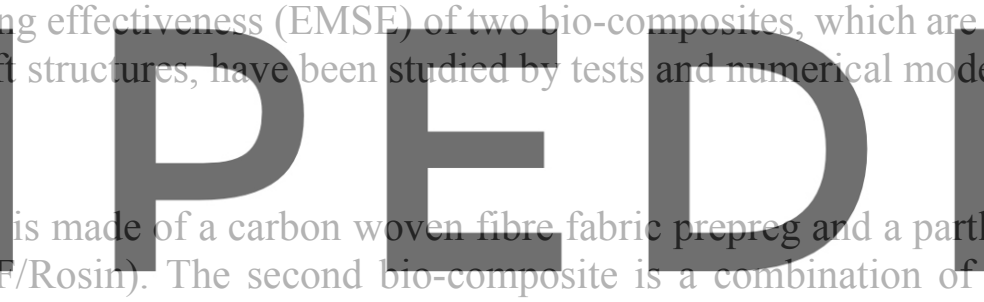

unidirectional carbon fibre fabric (5 layers in $0^{\circ}$ and $90^{\circ}$ direction) / epoxy resin and flax plain

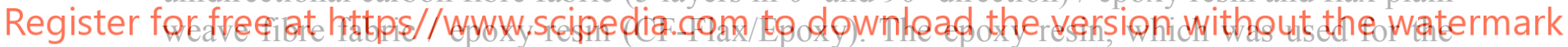

production of the second bio-composite, is the LY556 (HY+ DY). A single line infusion process

has been used prior to the curing step in the autoclave at $80^{\circ} \mathrm{C}$ for 4 hours with a post-curing at $120{ }^{\circ} \mathrm{C}$ for 4 hours. The prepreg layup of the first bio-composite was cured in the autoclave at $130{ }^{\circ} \mathrm{C}$ for 3 hours.

\section{EXPERIMENTAL}

\subsection{Electrical conductivity tests}

Electrical conductivity of bio-composites was derived from electrical resistivity. The electrical resistivity along $X$ (longitudinal) and $Z$ (normal) directions was measured according to AITM20064 [6] and AITM2-0065 standards [7], respectively. To this end, a plastic test-jig and a probe ohmmeter were used. Fig. 1(a) shows the specimen (coupon) used for the tests along $X$ axis inside the test-jig while Fig. 1(b) shows the specimen (plate) used for the tests along $\mathrm{Z}$ axis in between two brass plates. 

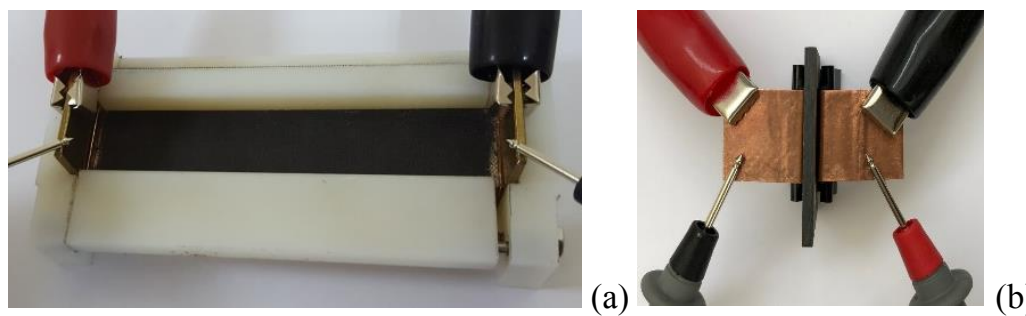

Figure 1: (a) The electrical resistivity test along $\mathrm{X}$ axis (b) the electrical resistivity test along $\mathrm{Z}$ axis

The resistance (in $\Omega$ ) of a parallelepipedic sample made from an isotropic material may be expressed as follows:

$$
R=\rho \times \frac{l}{s}=\rho \times \frac{l}{w \times t}
$$

where $\rho$ is the resistivity of the material, expressed in ohm meter $(\Omega \mathrm{m}), s$ the cross-sectional area of the specimen, expressed in squared meters $\left(\mathrm{m}^{2}\right), l, w$ and $t$ are respectively the length, the width and the thickness of the specimen, expressed in meters $(m)$.

The resistivity is an intrinsic property of the bulk material and may be represented as the resistance between the opposite faces of a 1-meter edge cube from this material. The

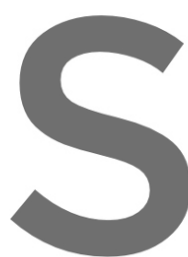
conductivity $\sigma$, expressed
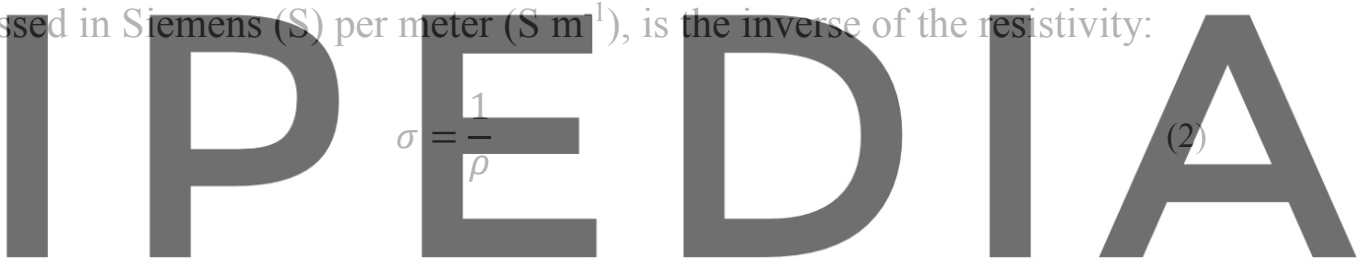

\subsection{EMSE tests}

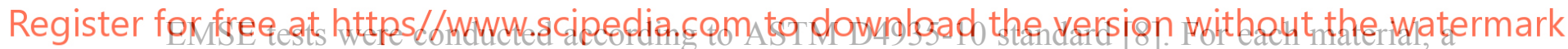

set of a reference and a load specimen of circular shape have been produced. The external diameter of the specimens is $133 \mathrm{~mm}$, while the intemal diameter of the reference specimen is $33 \mathrm{~mm}$. The specimens used in the EMSE tests are shown in Fig. 2. Both bio-composites are electrically thin according to the measured frequency bandwidth.

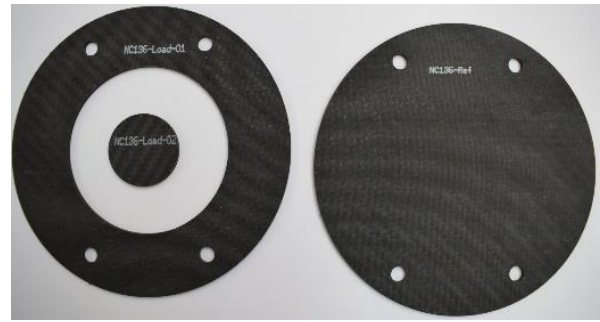

Figure 2: The specimens used in the EMC tests (left: reference, right: load). 
EMSE tests were conducted inside an anechoic chamber (Fig. 3) in order to ensure a clear environment from other EM interferences (noise-free environment). The EM wave was produced from a signal generator and was transmitted through a double-shielded cable. The specimens were placed into the specimen holder device. A set of N-type connectors were placed at both ends of the specimen holder to ensure a constant $50 \mathrm{Ohm}$ impedance. The signal was finally received by a receiver device.

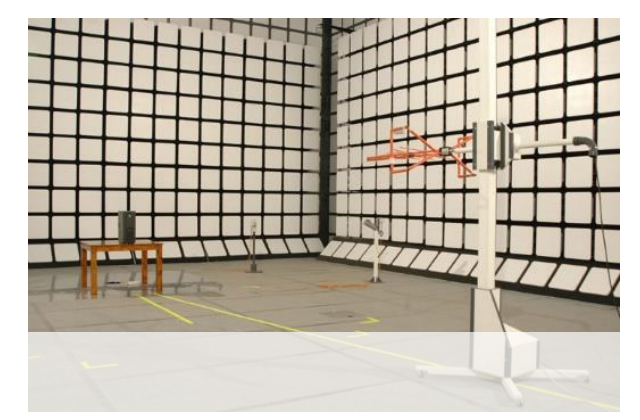

Figure 3: The anechoic chamber used for the EMSE tests.

The specimen holder (Fig. 4) is a bronze made apparatus manufactured according to the ASTM

D 4935-10 standard. A coaxial signal transmission is realized, as the device has a constant 50

Ohm impedance through its perfectly symmetrical structure (calibration of the device is been a

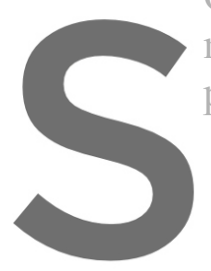

mandatory step

plastic fasteners. The
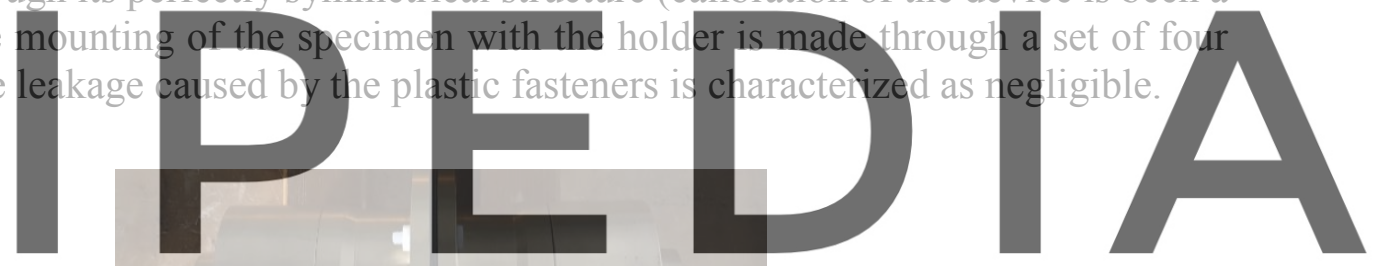

Register for free at https//www.scipedia.com to download the version without the watermark

Figure 4: The specimen holder used for the EMSE tests.

The signal generator has been set to produce an EM wave of $1 \mathrm{sec}$ total duration, starting from $30 \mathrm{MHz}$ to $1.5 \mathrm{GHz}$ with a step increment of $0.5 \mathrm{MHz}$. The system is been calibrated in order to avoid an energy leakage or a component mismatch (a constant value of $50 \mathrm{Ohm}$ is required). Inside the specimen holder (blank space) a far-field EM wave is formed that traverses through the testing material (load material case) in order to reach the holder's end. The receiver records the signal's power in $\mathrm{dBm}$ units (frequency bandwidth of $30 \mathrm{MHz}$ to $1.5 \mathrm{GHz}$ ). The measurements are made for both reference and load specimens. Shielding Effectiveness (SE) can be calculated directly from the $\mathrm{dBm}$ values or through conversion to $\mathrm{mWatt}$ units

$$
S E=-\left(\mathrm{dBm}_{r e f}-\mathrm{dBm}_{\text {load }}\right)
$$




\section{NUMERICAL ANALYSIS}

Additional to the tests, electrical conductivity of bio-composites was predicted by numerical analysis which is based on representative volume elements (RVEs). To this end, the DIGIMAT software was used. For the development of the RVEs, it was crucial to have information on the microstructure and electrical properties of the materials (Table 1). The developed RVEs are shown in Fig. 5. The RVEs were meshed using a built-in mesh generator, with second order tetrahedral elements, instead of voxel elements [9-10]. The FE meshes of the RVEs are also illustrated in Fig. 5. The RVEs were loaded using periodic boundary conditions to achieve homogenization.

Table 1: Physical and electrical properties of materials

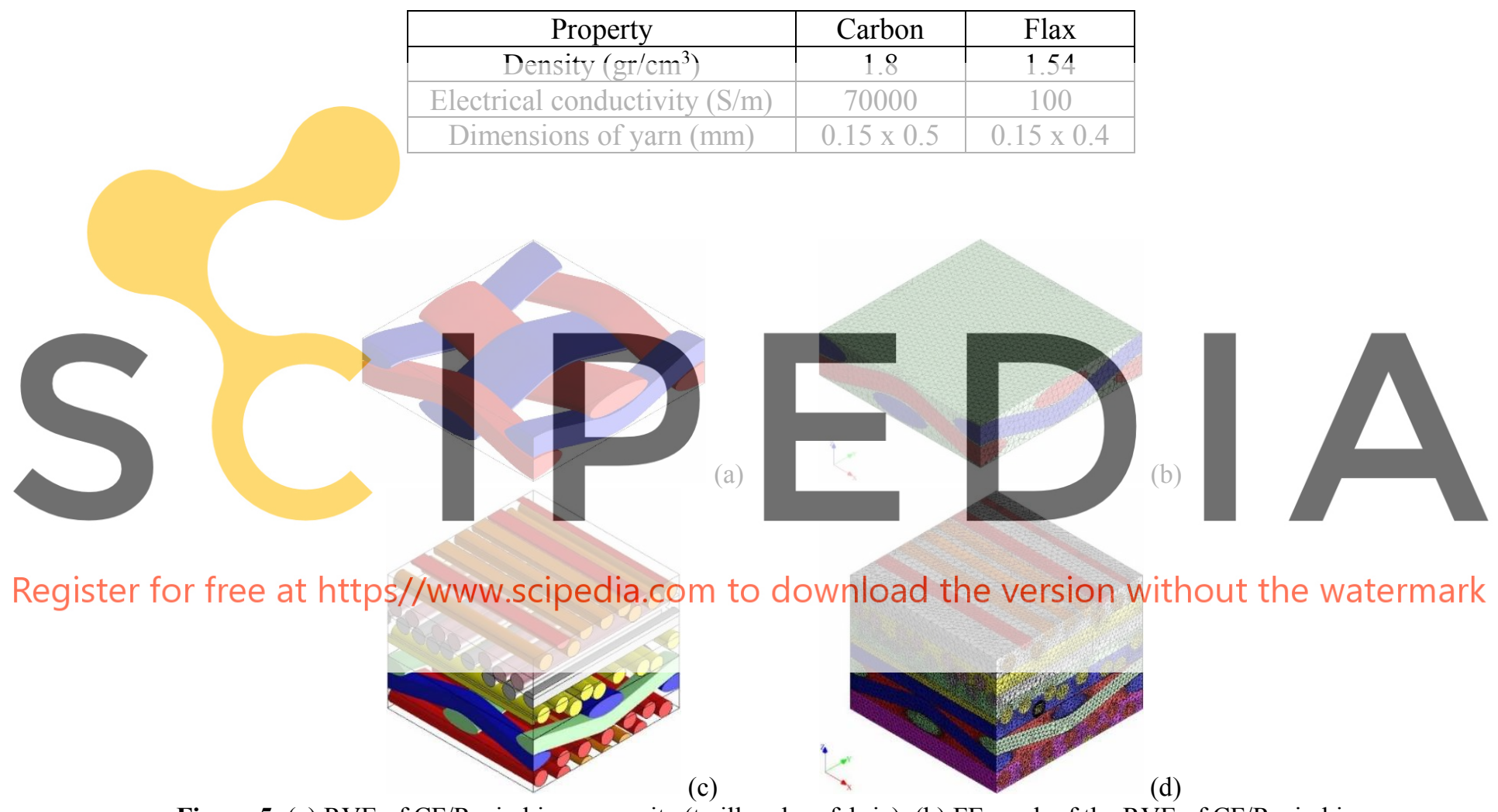

Figure 5: (a) RVE of CF/Rosin bio-composite (twill carbon fabric), (b) FE mesh of the RVE of CF/Rosin biocomposite, (c) RVE of CF/Flax-Resin bio-composite (d) FE mesh of the RVE of CF/Flax-Resin bio-composite. 


\section{EXPERIMENTAL RESULTS}

\subsection{Electrical conductivity}

The measured electrical conductivity values of the bio-composites are displayed in Fig. 6. The average conductivity of the $\mathrm{CF} / \mathrm{Rosin}$ bio-composite is $11491 \mathrm{~S} / \mathrm{m}$ and the standard deviation is $558 \mathrm{~S} / \mathrm{m}$. The average conductivity of the CF/Flax-Epoxy bio-composite is $15104 \mathrm{~S} / \mathrm{m}$ and the standard deviation is $4858 \mathrm{~S} / \mathrm{m}$. The relatively high standard deviation electrical conductivity for the CF/Flax-Epoxy material is due to the variation of metallization quality of the flax fiber surface and due to the variation of fiber volume fraction through the dimensions of the specimens. Fig. 7 shows a metallized flax fiber surface with many defects. The measured electrical conductivities of the bio-composites lie in the area of the lower limit of the electrical conductivity of CFRPs $(\sim 12,000 \mathrm{~S} / \mathrm{m})$ [11-12].
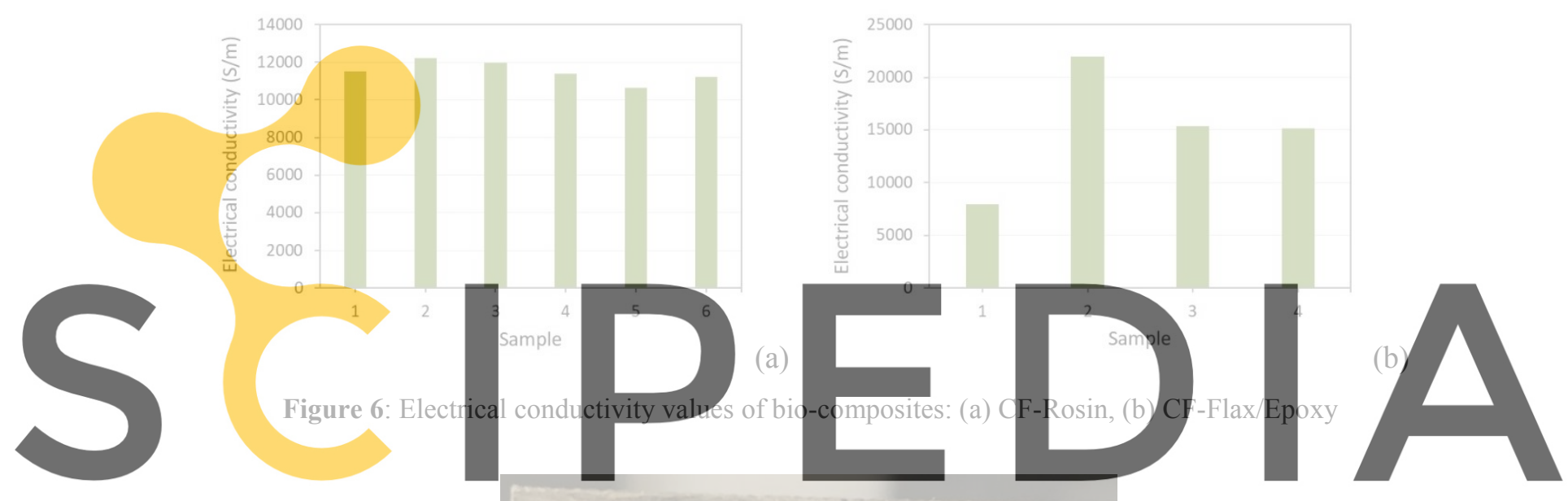

Register for free at https//www.scipedia.com to download the version without the watermark

Figure 7: Metallization of the hybrid (Carbon \flax composite)

\subsection{EMSE}

EMSE tests were conducted under continuous loading, from $30 \mathrm{MHz}$ and $1.5 \mathrm{GHz}$ with increment step of $0.5 \mathrm{MHz}$ for both reference and load specimens. Inside of the specimen holder a far-field wave is formed that propagates through the testing material (when load specimen is tested) and reaches the receiver which records the signal's power. The received signals are plotted in Figs. 8 and 9 in terms of signal's amplitude versus frequency. The SE is derived from Eq. (3). The results show that both materials exhibit a higher SE at high frequency EM waves. More specific, the maximum SE for the CF/Rosin material is $81.05 \mathrm{~dB}$ at $1363 \mathrm{MHz}$ and for the CF/Flax-Epoxy material is $86.15 \mathrm{~dB}$ at $1417 \mathrm{MHz}$. The minimum SE values for the two materials is $38.89 \mathrm{~dB}$ and $36.68 \mathrm{~dB}$, respectively, both achieved at $30 \mathrm{MHz}$ (low EM frequencies). The values above $60 \mathrm{~dB}$ (up to $90 \mathrm{~dB}$ ) provide sufficient EM protection [13-14]. 


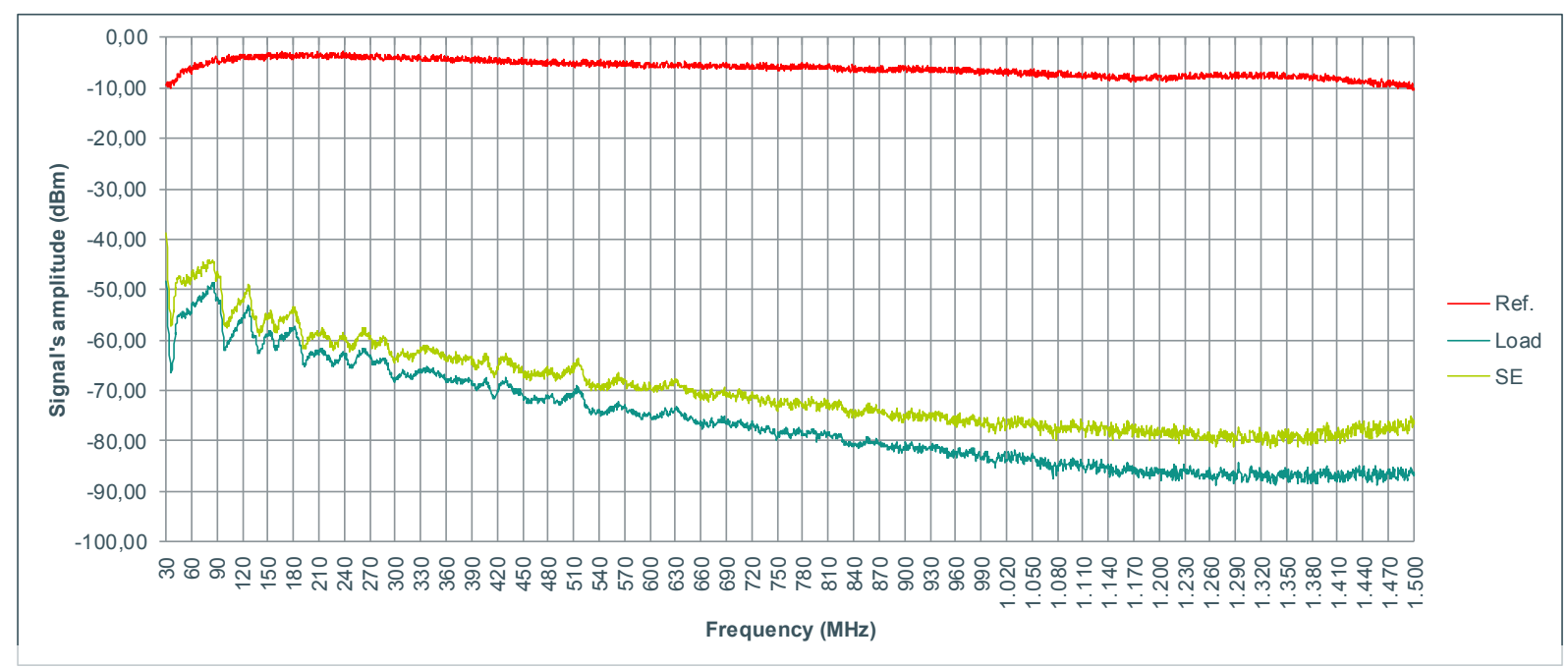

Figure 8: Signal' amplitude vs. frequency for the CF/Rosin bio-composite

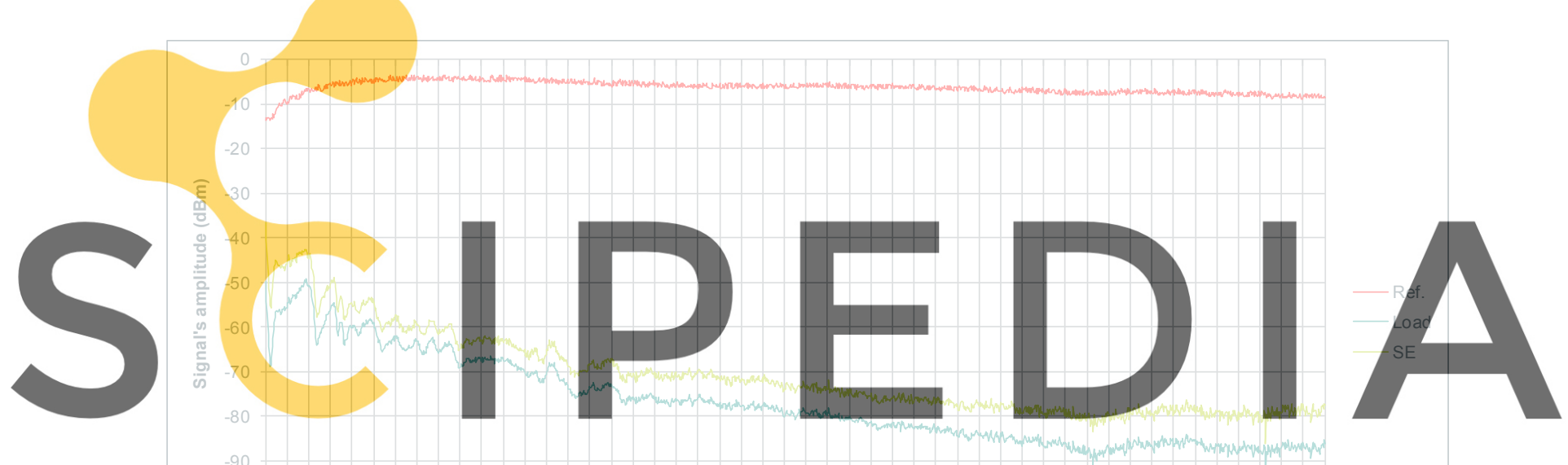

Register for free at https//www.scipedia.com to download the version without the watermark

Frequency $(\mathrm{MHz})$

Figure 9: Signal' amplitude vs. frequency for the CF/Flax-Epoxy bio-composite

\section{NUMERICAL RESULTS}

The computed electrical conductivity is $12357 \mathrm{~S} / \mathrm{m}$ for the CF/Rosin bio-composite and 14333 $\mathrm{S} / \mathrm{m}$ for the CF/Flax-Epoxy bio-composite. Both predicted values compare very well with the average experimental values (11491 S/m and $15104 \mathrm{~S} / \mathrm{m}$, respectively).

\section{CONCLUSIONS}

In this paper, the electrical conductivity and EMSE of a CF/Rosin bio-composite and a CF/FlaxEpoxy bio-composite, which are intended for use in secondary aircraft structures, have been studied by tests and numerical models. The findings show a potential of the bio-composites since the measured electrical conductivities and the SE although being smaller than the 
respective values of CFRPs, they are within the acceptable deviation range. Furthermore, the RVE-based numerical model has given very good predictions on electrical conductivity of the bio-composites.

\section{ACKNOWLEDGEMENT}

The work reported in this paper has received funding from the European Union's Horizon 2020 research and innovation programme ECO-COMPASS (Grant no. 690638).

\section{REFERENCES}

[1] Bachmann, J., Yi, X., Gong, H., Martinez, X., Bugeda, G., Oller, S., Tserpes, K., Ramon, E., Paris, C., Moreira, P., Fang, Z., Li, Y., Liu, Y., Liu, X., Xian, G., Tong, J., Wei, J., Zhang, X., Zhu, J., Ma, S. and Yu, T. (2018). Outlook on ecologically improved composites for aviation interior and secondary structures. CEAS Aeronautical Journal, 9(3), pp. 533-543.

[2] Yi, X. and Tserpes, K. (2019). Special Issue "ECO-COMPASS: Ecological and Multifunctional Composites for Application in Aircraft Interior and Secondary Structures". Aerospace, 6(2), p.17.

[3] Rakov, V. and Rachidi, F. (2009). Overview of Recent Progress in Lightning Research and Lightning Protection. IEEE Transactions on Electromagnetic Compatibility, 51(3)

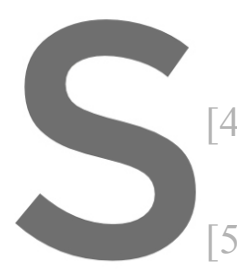
pp.428-442.

4] White, D. and Interference Contro Rifai, A. and Hakami, M. (2014). Health Etectromagnetic shielding. Gainesville, Journal of Biosciences and Medicines, 02(08), pp.1-12.

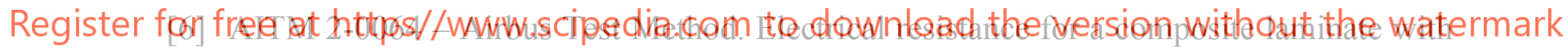
carbon fibre: Measurement along X or Y direction.

[7] AITM 2-0065 Airbus Test Method. Electrical resistance for a composite laminate with carbon fibre: Measurement along $\mathrm{Z}$ direction.

[8] ASTM D4935 - 10 Standard Test Method for Measuring the Electromagnetic Shielding Effectiveness of Planar Materials

[9] Zienkiewicz, O.C. and Taylor, R.L. The finite element method. McGraw Hill, Vol. I., (1989), Vol. II, (1991).

[10] Idelsohn, S.R. and Oñate, E. Finite element and finite volumes. Two good friends. Int. J. Num. Meth. Engng (1994) 37:3323-3341.

[11] Alexandre Piche, Gilles Peres and Ivan Revel (2011). Experimental and Numerical Methods to Characterize Electrical Behaviour of Carbon Fiber Composites Used in Aeronautic Industry. INTECH Open Access Publisher.

[12] Si-Ping Gao, Hui Min Lee, Richard Xian-Ke Gao, Qi Feng Lim, Warintorn Thitsartarn, En-Xiao Liu and Ching Eng Png (2017). Effective Modeling of Multidirectional CFRP 
Panels Based on Characterizing Unidirectional Samples for Studying the Lightning Direct Effect. [online] Available at: https://ieeexplore.ieee.org/document/8105177 [Accessed 18 Apr. 2019].

[13] Daniela Munalli, Dimitrios Chronopoulos and Steve Greedy (2018). Electromagnetic shielding effectiveness of fiber-reinforced composites: a preliminary study. In: 9th European Workshop on Structural Health Monitoring. [online] Manchester, United Kingdom.

[14] Tugirumubano, A., Vijay, S., Go, S., Kwac, L. and Kim, H. (2018). Investigation of Mechanical and Electromagnetic Interference Shielding Properties of Nickel-CFRP Textile Composites. Journal of Materials Engineering and Performance, 27(5), pp.22552262.
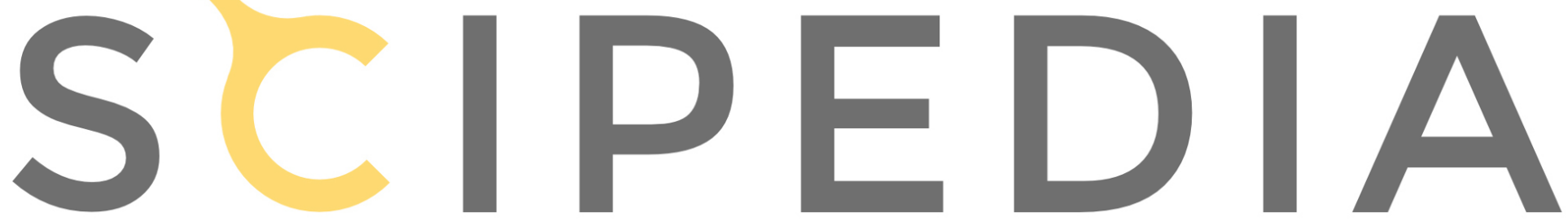

Register for free at https//www.scipedia.com to download the version without the watermark 